\title{
Novel $\mathrm{Co}_{3} \mathrm{O}_{4}$ Nanoparticles/Nitrogen-Doped Carbon Composites with Extraordinary Catalytic Activity for Oxygen Evolution Reaction (OER)
}

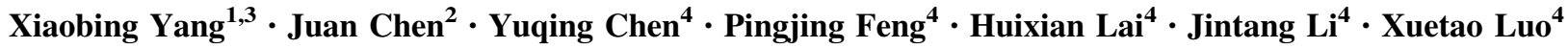

Received: 21 August 2017/Accepted: 8 October 2017/Published online: 14 November 2017

(C) The Author(s) 2017. This article is an open access publication

\section{Highlights}

- $\mathrm{Co}_{3} \mathrm{O}_{4}$ nanoparticles/nitrogen-doped carbon $\left(\mathrm{Co}_{3} \mathrm{O}_{4} / \mathrm{NPC}\right)$ composites were successfully fabricated from zeolitic imidazolate framework 67 (ZIF-67), and the composite structure could be well controlled by adjusting the structure of ZIF67.

- $\mathrm{M}-\mathrm{Co}_{3} \mathrm{O}_{4} / \mathrm{NPC}$ composites derived from flower-like ZIF-67 showed the highest activities for the oxygen evolution reaction (OER).

\begin{abstract}
Herein, $\mathrm{Co}_{3} \mathrm{O}_{4}$ nanoparticles/nitrogen-doped carbon $\left(\mathrm{Co}_{3} \mathrm{O}_{4} / \mathrm{NPC}\right)$ composites with different structures were prepared via a facile method. Structure control was achieved by the rational morphology design of ZIF-67 precursors, which were then pyrolyzed in air to obtain $\mathrm{Co}_{3} \mathrm{O}_{4} / \mathrm{NPC}$ composites. When applied as catalysts for the oxygen evolution reaction (OER), the $\mathrm{M}-\mathrm{Co}_{3} \mathrm{O}_{4} / \mathrm{NPC}$ composites derived from the flower-like ZIF-67 showed
\end{abstract}

Juan Chen and Xiaobing Yang have contributed equally to this work.

Electronic supplementary material The online version of this article (https://doi.org/10.1007/s40820-017-0170-4) contains supplementary material, which is available to authorized users.

\section{Xuetao Luo}

xuetao@xmu.edu.cn

1 College of Ecology and Resource Engineering, Wuyi University, Wuyishan 354300, Fujian, People's Republic of China

2 Department of Pharmacy, Zhongshan Hospital, Xiamen University, Xiamen 361004, Fujian, People's Republic of China

3 Fujian Provincial Key Laboratory of Eco-Industrial Green Technology, Wuyi University, Wuyishan 354300, Fujian, People's Republic of China

4 Fujian Key Laboratory of Advanced Materials, College of Materials, Xiamen University, Xiamen 361005, Fujian, People's Republic of China

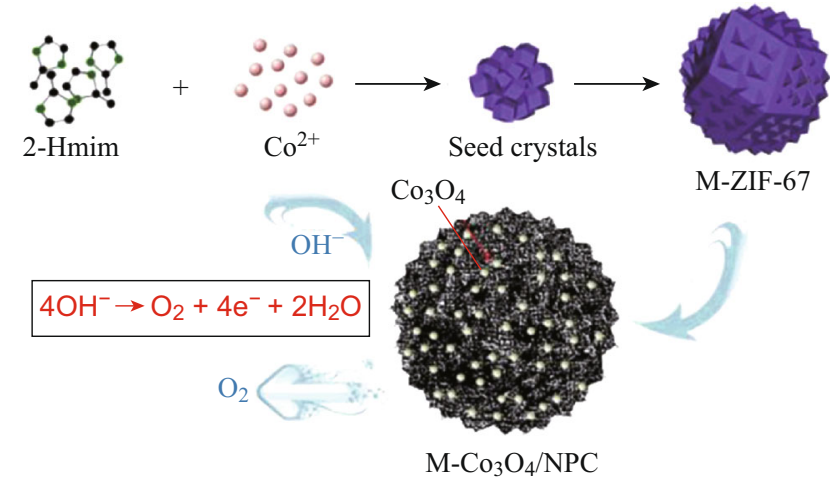

superior catalytic activities than those derived from the rhombic dodecahedron and hollow spherical ZIF-67. The former $\mathrm{M}-\mathrm{Co}_{3} \mathrm{O}_{4} / \mathrm{NPC}$ composite displayed a small overpotential of $0.3 \mathrm{~V}$, low onset potential of $1.41 \mathrm{~V}$, small Tafel slope of $83 \mathrm{mV} \mathrm{dec}{ }^{-1}$, and a desirable stability. (94.7\% OER activity was retained after $10 \mathrm{~h}$.) The excellent performance of the flower-like $\mathrm{M}-\mathrm{Co}_{3} \mathrm{O}_{4} / \mathrm{NPC}$ composite in the OER was attributed to its favorable structure.

Keywords $\mathrm{Co}_{3} \mathrm{O}_{4}$ nanoparticles $\cdot$ Nitrogen-doped carbon . ZIF-67 - Catalytic · Oxygen evolution reaction (OER) 


\section{Introduction}

Depletion of fossil fuels and the rapidly growing energy demands have necessitated the development of sustainable energy conversion and storage systems such as metal-air batteries, water splitting devices, and fuel cells [1-4]. The development of durable, highly efficient, low-cost, and eco-friendly electrocatalysts for the oxygen evolution reaction (OER) is crucial for the commercial application of these renewable energy technologies $[5,6]$. To date, precious metal-based materials, such as $\mathrm{RuO}_{2}$ and $\mathrm{IrO}_{2}$, have been considered as the most optimal catalysts for OER owing to their lowest over-potentials at practical current densities [7]. However, their commercial applications have been severely impeded because of their poor stability, prohibitive cost, and low selectivity [8].

Recently, significant efforts have been made to explore transition metal-based electrocatalysts for the OER because of their low cost, abundant reserves, environmental benignity, and resistance to corrosion in alkaline solutions [9-12]. Among them, Co-based catalysts have emerged as promising alternatives for precious metal-based catalysts [13-16]. The electrocatalytic activity for OER is closely related to the active sites and electronic conductivity of the catalysts. Previous research has demonstrated that active sites can be engineered by modulating the particle size, pore structure $[17,18]$, and the crystallinity $[19,20]$ of $\mathrm{Co}_{3} \mathrm{O}_{4}$. Furthermore, coupling with carbon effectively improves the electronic conductivity of the catalysts [21-23]. Nevertheless, carbon itself as a catalyst displays relatively low catalytic OER activity. Recent studies have shown that doping with either nitrogen or transition metals into carbon nanostructure can efficiently promote its catalytic performance [23-26]. The template method has proven to be an effective protocol for obtaining nitrogendoped $\mathrm{Co}_{3} \mathrm{O}_{4} / \mathrm{C}$ composites. In this method, various organic hybrids, which contain both the transition metal and nitrogen, are used as precursors such as melamine [27], porphyrin [28], polyaniline [29, 30], and salen [31]. However, it is hard to control the size, structure, and morphology of these organic hybrids in an exact manner; therefore, deficiencies and non-uniform distributions of active sites are prevalent, which are also crucial for electrocatalytic activity.

Metal organic frameworks (MOFs) have attracted a significant attention as materials for the preparation of nonprecious metal electrocatalysts because of their inherent advantages such as a controllable porous structure, innate doping with heteroatoms, and an ultrahigh surface area $[32,33]$. Zeolitic imidazolate frameworks (ZIFs) have proven to be promising as pyrolytic precursors for various porous metal oxides/doped carbon composites [34-36]. Via direct pyrolysis, carbon layers with a porous structure can be formed in situ with metal nanoparticles encapsulated homogeneously, and sufficient contacts can be formed between the metal nanoparticles and the carbon matrix. Notably, a highly ordered three-dimensional structure promotes the structural stability of MOFs against pyrolysis, and the remarkable surface-to-volume ratio of MOFs can effectively promote the electrochemical catalytic reactions.

Among the variety of MOF materials available, ZIF-67 is one of the most widely investigated ones because of its high concentration of active cobalt sites as well as a facile synthetic method. Herein we have proposed a facile method to prepare $\mathrm{Co}_{3} \mathrm{O}_{4} / \mathrm{NPC}$ composites with different morphologies derived from ZIF-67. By slightly modulating the synthetic route of the ZIF-67 precursors, it was possible to control the morphology of the product. Thus, in addition to the typical rhombic dodecahedron morphology, novel flower-like ZIF-67 and hollow spherical ZIF-67 were fabricated. These ZIF-67 precursors were then pyrolyzed to obtain the $\mathrm{Co}_{3} \mathrm{O}_{4} / \mathrm{NPC}$ composites of different structures, named T- $-\mathrm{Co}_{3} \mathrm{O}_{4} / \mathrm{NPC}, \mathrm{M}-\mathrm{Co}_{3} \mathrm{O}_{4} / \mathrm{NPC}$, and $\mathrm{H}-\mathrm{Co}_{3} \mathrm{O}_{4} / \mathrm{NPC}$, respectively. The electrocatalytic activities for OER of the three composites were then investigated to determine the most favorable morphology for the highest electrocatalytic performance for the OER.

\section{Experimental}

\subsection{Chemicals}

Cobalt nitrate hexahydrate $\left(\mathrm{Co}\left(\mathrm{NO}_{3}\right)_{2} \cdot 6 \mathrm{H}_{2} \mathrm{O},>99.8 \%\right)$ was purchased from Shanghai Titanchem Co. Ltd., and methanol $\left(\mathrm{CH}_{3} \mathrm{OH},>99.5 \%\right)$, cobalt sulfate heptahydrate $\left(\mathrm{CoSO}_{4} \cdot 7 \mathrm{H}_{2} \mathrm{O},>99.8 \%\right)$, 2-methylimidazole $\left(\mathrm{C}_{4} \mathrm{H}_{6} \mathrm{~N}_{2}\right.$, $99 \%)$, and polyvinylpyrrolidone $\left(\left(\mathrm{C}_{6} \mathrm{H}_{9} \mathrm{NO}\right)_{n}\right)$ were obtained from Sinopharm Chemical Reagent Co. Ltd. All reagents were used as received without further purification.

\subsection{Preparation of ZIF-67 Precursors}

T-ZIF-67 was synthesized according to a previously reported method [37]. In a typical procedure, solutions of $\mathrm{Co}\left(\mathrm{NO}_{3}\right)_{2} \cdot 6 \mathrm{H}_{2} \mathrm{O}(5.82 \mathrm{~g})$ in methanol $(400 \mathrm{~mL})$ (solution A) and 2-methylimidazole $(6.48 \mathrm{~g})$ in methanol $(400 \mathrm{~mL})$ (solution B) were prepared. Solution B was gradually added into solution A with continuous stirring. After standing for a while, layers were observed and the supernatant was eliminated. The solution was then centrifuged and washed with methanol for 3-5 times to remove the excess $\mathrm{Co}^{2+}$. T-ZIF-67 was finally acquired as a purple solid after drying at $60{ }^{\circ} \mathrm{C}$ for $3 \mathrm{~h}$. 
The synthetic route to M-ZIF-67 was almost the same as that of T-ZIF-67, except that $\mathrm{Co}\left(\mathrm{NO}_{3}\right)_{2} \cdot 6 \mathrm{H}_{2} \mathrm{O}$ was replaced by $\mathrm{CoSO}_{4} \cdot 7 \mathrm{H}_{2} \mathrm{O}(5.62 \mathrm{~g})$. During the synthesis of $\mathrm{H}-\mathrm{ZIF}$ $67,1.00 \mathrm{~g}$ PVP was added to the methanol solution of 2-methylimidazole as a morphology modifier, and other steps were the same as that for the synthesis of M-ZIF-67.

\subsection{Preparation of $\mathrm{Co}_{3} \mathrm{O}_{4} / \mathrm{NPC}$ Composites}

The as-prepared M-ZIF-67, H-ZIF-67, and T-ZIF-67 materials were first ground into powders. They were then individually heated to $550{ }^{\circ} \mathrm{C}$ in air at a heating rate of $5{ }^{\circ} \mathrm{C} \min ^{-1}$. After keeping at $550{ }^{\circ} \mathrm{C}$ for $5 \mathrm{~h}$, the powdered materials were cooled down to room temperature at a cooling rate of $5^{\circ} \mathrm{C} \mathrm{min}^{-1}$ and black $\mathrm{M}-\mathrm{Co}_{3} \mathrm{O}_{4} / \mathrm{NPC}$, $\mathrm{H}-\mathrm{Co}_{3} \mathrm{O}_{4} / \mathrm{NPC}$, and $\mathrm{T}-\mathrm{Co}_{3} \mathrm{O}_{4} / \mathrm{NPC}$ powders were obtained, respectively.

\subsection{Characterization}

Powder X-ray diffraction (PXRD) analysis of the materials was performed on a Bruker-AXS D8 Advance X-ray diffractometer with $\mathrm{Cu} \mathrm{K} \alpha$ radiation $(\lambda=0.15406 \mathrm{~nm})$. The morphologies and elemental mappings of the samples were obtained from a Hitachi SU70 field-emission scanning electron microscopy (SEM) instrument at $10 \mathrm{kV}$ and $20 \mathrm{kV}$. The high-resolution transmission electron microscopy (HRTEM) characterization was carried out on a Tecnai F30 microscope at an accelerating voltage of 300 $\mathrm{kV}$. Elemental analysis was performed on a Vario EL III elemental analyzer. The specific surface area and pore size distribution were determined by the Brunauer-EmmettTeller (BET) method conducted by the TriStar II 3020 surface area and porosity analyzer. Thermogravimetric analysis (TGA) of the samples was carried out on a SDTQ600 thermoanalyzer in air. X-ray photoelectron spectroscopy (XPS) was performed on a Thermo Scientific ESCALAB 250Xi with Al Ka radiation $(h v=1486.8 \mathrm{eV})$.

\subsection{Electrochemical Measurements}

Cyclic voltammetry (CV) and linear sweep voltammetry (LSV) measurements were taken on an Autolab PGSTAT302N electrochemical workstation (NOVA 1.9). The evaluation of the catalytic activity for the OER was conducted at room temperature in a conventional threeelectrode system. $\mathrm{Co}_{3} \mathrm{O}_{4} / \mathrm{NPC}$ composites were used as the working electrode, a platinum foil acted as a counter electrode, and a reversible hydrogen electrode (RHE) was employed as the reference electrode. To prepare the working electrode, $5 \mathrm{mg}$ of the active material was dispersed in a mixture of $0.95 \mathrm{~mL}$ ethanol and $0.05 \mathrm{~mL} 5$ wt\% Nafion solution with sonication for $60 \mathrm{~min}$. Next, the catalyst $(20 \mu \mathrm{L})$ was pipetted out and dropped onto a glassy carbon electrode with a diameter of $5 \mathrm{~mm}$. It was then fully dried at room temperature for $12 \mathrm{~h}$ before measurements (loading $\sim 0.510 \mathrm{mg} \mathrm{cm}^{-2}$ ).

\section{Results and Discussion}

Figure S1 shows the PXRD patterns of M-ZIF-67, H-ZIF67, and T-ZIF-67. Apparently, these three materials exhibit the same XRD pattern with principal diffraction peaks at $7.39^{\circ}, 10.43^{\circ}, 12.73^{\circ}$, and $18.07^{\circ}$, which are exactly matched with the simulated ZIF-67 pattern. This suggests that the three ZIFs have the same composition. This result was also supported by their FTIR spectra (Fig. S2). The diffraction peaks of T-ZIF-67 were much higher than those of M-ZIF-67 and H-ZIF-67, implying a higher crystallinity of T-ZIF-67 in comparison with the other two ZIF-67 precursors.

The morphologies of the ZIF-67 precursors and the asprepared $\mathrm{Co}_{3} \mathrm{O}_{4} / \mathrm{NPC}$ composites were studied by SEM. T-ZIF-67 showed a rhombic dodecahedron morphology with particle sizes of $\sim 1 \mu \mathrm{m}$, which is the typical morphology of ZIF-67 (Fig. 1a). On the other hand, the morphology of M-ZIF-67 was flower-like with particles of size $\sim 1.6 \mu \mathrm{m}$ (Fig. 1b) and that of H-ZIF-67 was hollow spherical with a diameter of $\sim 800 \mathrm{~nm}$ and shell thickness $\sim 200 \mathrm{~nm}$ (Fig. 1g, h). After pyrolysis at $550{ }^{\circ} \mathrm{C}$ for $5 \mathrm{~h}$ under air, all three ZIF-67-derived composites inherited the morphologies of their precursors without either particle agglomeration (Fig. S3) or structural collapse, indicating a high structural stability of the obtained $\mathrm{Co}_{3} \mathrm{O}_{4} / \mathrm{NPC}$ composites. Specifically, the surfaces of T-ZIF-67 shrunk into a rhombic dodecahedron center with $\mathrm{Co}_{3} \mathrm{O}_{4}$ nanoparticles uniformly embedded in the carbon scaffold (Fig. 1b). M-ZIF-67 and T-ZIF-67 underwent similar changes in morphology to yield $\mathrm{M}-\mathrm{Co}_{3} \mathrm{O}_{4} / \mathrm{NPC}$ (Fig. 1e) and $\mathrm{H}-\mathrm{Co}_{3} \mathrm{O}_{4} / \mathrm{NPC}$ (Fig. 1h), respectively. To determine the elemental composition of the composites, elemental mapping analysis was conducted. As shown in Fig. 1c, f, i and Table S1, all three composites were mainly comprised of cobalt and oxygen, with trace amounts of carbon and nitrogen. This implied that the pyrolysis of ZIF-67 yields a nitrogen-doped carbon scaffold encapsulated in situ with $\mathrm{Co}_{3} \mathrm{O}_{4}$ nanoparticles. Further detailed investigations were performed by using HRTEM (Fig. 2). The $\mathrm{Co}_{3} \mathrm{O}_{4}$ nanoparticles adsorbed on the $\mathrm{M}-\mathrm{Co}_{3} \mathrm{O}_{4} / \mathrm{NPC}$ and $\mathrm{H}-\mathrm{Co}_{3} \mathrm{O}_{4} / \mathrm{NPC}$ composites were of similar sizes at $\sim 12 \mathrm{~nm}$. The lattice distance in the related high-resolution TEM images matched the (311) interplanar distance of the $\mathrm{Co}_{3} \mathrm{O}_{4}$ nanoparticles. 

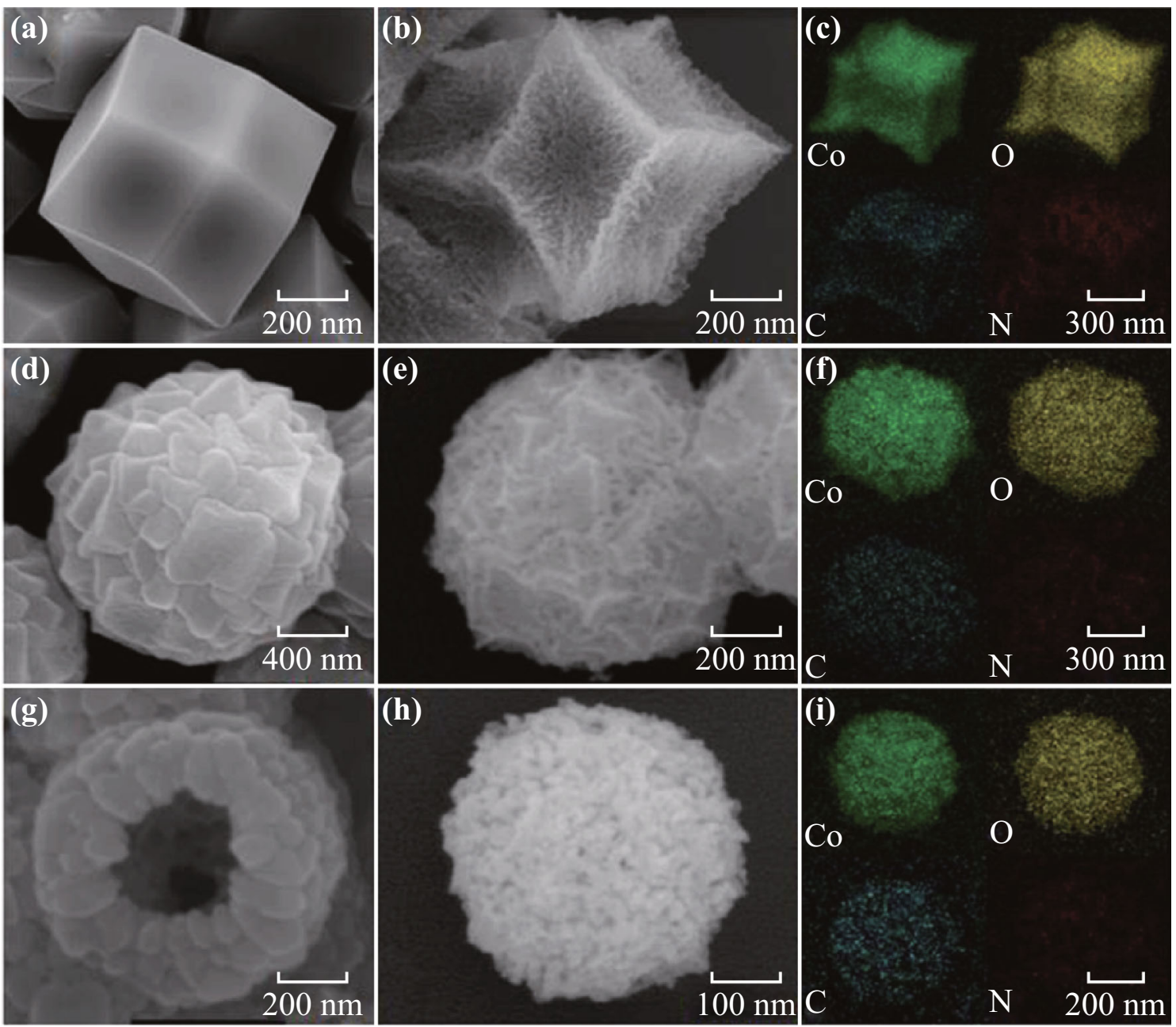

Fig. 1 SEM images of a T-ZIF-67, b T- $\mathrm{Co}_{3} \mathrm{O}_{4} / \mathrm{NPC}$, d M-ZIF-67, e M- $\mathrm{Co}_{3} \mathrm{O}_{4} / \mathrm{NPC}, \mathbf{g} \mathrm{H}-\mathrm{ZIF}-67$, and h $\mathrm{H}_{-} \mathrm{Co}_{3} \mathrm{O}_{4} / \mathrm{NPC}$. Elemental mapping of c T- $\mathrm{Co}_{3} \mathrm{O}_{4} / \mathrm{NPC}$, f $\mathrm{M}-\mathrm{Co}_{3} \mathrm{O}_{4} / \mathrm{NPC}$, and i $\mathrm{H}-\mathrm{Co}_{3} \mathrm{O}_{4} / \mathrm{NPC}$

To clearly illustrate the process of morphology control, the schematic diagrams of the synthetic procedure are presented in Fig. 3. In the traditional synthetic method of ZIF-67, $\mathrm{Co}\left(\mathrm{NO}_{3}\right)_{2} \cdot 6 \mathrm{H}_{2} \mathrm{O}$ has been used as the metal source. In this work, we used $\mathrm{CoSO}_{4} \cdot 7 \mathrm{H}_{2} \mathrm{O}$ as the metal source instead. The introduction of $\mathrm{SO}_{4}{ }^{2+}$ species accelerated the nucleation of ZIF-67, leading to multiple polyhedrons being embedded mutually, until finally flower-like ZIF-67 particles had formed. As for H-ZIF-67, PVP was employed as a template. As shown in Fig. 3, 2-methylimidazole combined with the PVP molecular chain via hydrogen bonds when they were dissolved together in methanol. This interaction between the ligands and the template forced ZIF-67 to grow along the chain, resulting in flake-like ZIF67, which then piled together to form a hollow sphere.

The PXRD patterns of the $\mathrm{T}-\mathrm{Co}_{3} \mathrm{O}_{4} / \mathrm{NPC}, \mathrm{M}-\mathrm{Co}_{3} \mathrm{O}_{4} /$ NPC, and $\mathrm{H}-\mathrm{Co}_{3} \mathrm{O}_{4} / \mathrm{NPC}$ composites were obtained to investigate their compositions. As shown in Fig. 4, apart from the differences in diffraction intensities, the XRD patterns of the three composites were the same. Peaks at $31.27^{\circ}, 36.85^{\circ}, 44.81^{\circ}, 59.36^{\circ}$, and $65.24^{\circ}$ could be indexed to the (220), (311), (400), (511), and (440) planes of spinel cobalt oxide (JCPDS No. 42-1467), respectively. Since intense diffractions imply higher degree of crystallinity, it was concluded that the structure of $\mathrm{M}-\mathrm{Co}_{3} \mathrm{O}_{4} /$ NPC was the least ordered.

To gain an in-depth understanding of the pore structure of the three composites, the nitrogen adsorption-desorption isotherms and the corresponding pore size distribution curves of ZIF-67 precursors and $\mathrm{Co}_{3} \mathrm{O}_{4} / \mathrm{NPC}$ composites were determined. As shown in Fig. $5 \mathrm{a}$, the nitrogen adsorption-desorption isotherms of M-ZIF-67, H-ZIF-67, and T-ZIF-67 agreed with Langmuir I. In M-ZIF-67, the quantity of adsorbed $\mathrm{N}_{2}$ increased dramatically at a low relative pressure, indicating abundant micropores in the flower-like particles. Besides, at the tail of the isotherm (high relative pressure), the absorbance increased quickly, suggesting a large amount of mesopores. Similarly, T-ZIF- 

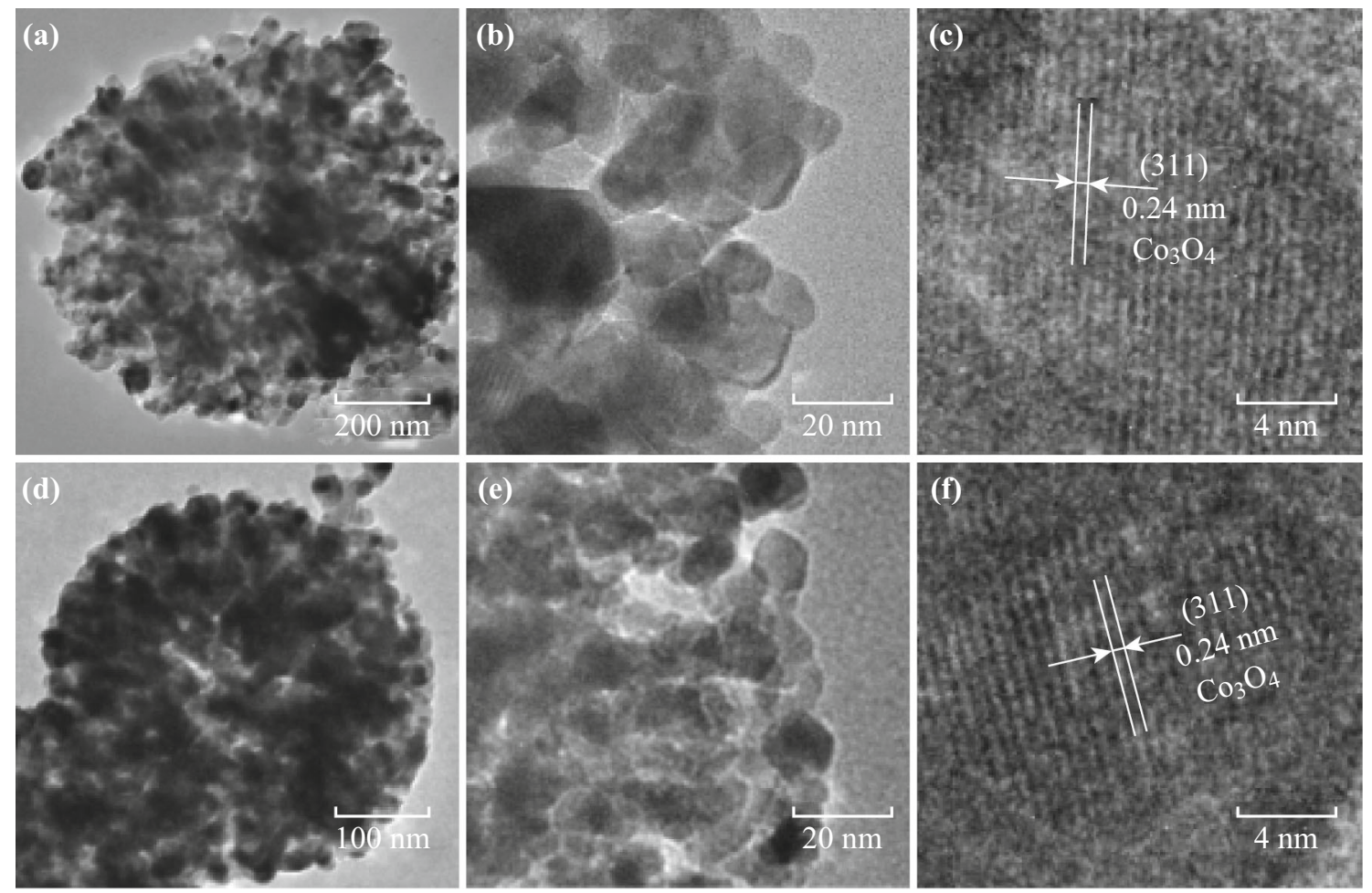

Fig. 2 TEM images of a-c $\mathrm{M}-\mathrm{Co}_{3} \mathrm{O}_{4} / \mathrm{NPC}$ and d-f $\mathrm{H}-\mathrm{Co}_{3} \mathrm{O}_{4} / \mathrm{NPC}$ composites

$$
\cdot \mathrm{N} \cdot \mathrm{C} \rightleftharpoons \mathrm{PVP} \backslash \mathrm{Co}
$$
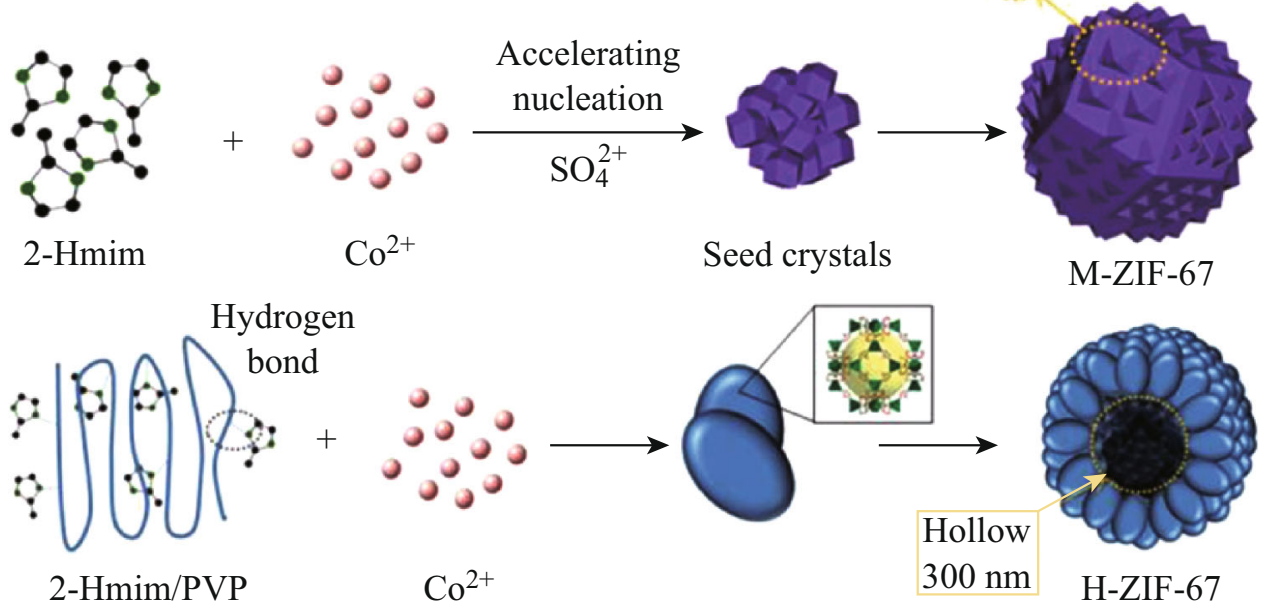

Fig. 3 Schematic diagram of the preparation of a M-ZIF-67 and b H-ZIF-67

67 possessed numerous micropores with a relatively negligible number of mesopores. In contrast, H-ZIF-67 had much less of both micro- and mesopores. These differences are also evident in the pore size distribution curves (Fig. 5b). The BET surfaces of M-ZIF-67, H-ZIF-67, and T-ZIF-67 were determined to be 2375.343, 149.292, and $1187.203 \mathrm{~m}^{2} \mathrm{~g}^{-1}$, respectively. Accordingly, after pyrolysis, their BET surface areas were $25.869,2.742$, and $11.703 \mathrm{~m}^{2} \mathrm{~g}^{-1}$, respectively. Noticeably, the adsorption type changed from Langmuir I to Langmuir III after pyrolysis (Fig. $5 \mathrm{c}$ ), and the pore sizes became larger and the distribution was more dispersive (Fig. 5d). On the basis of these results, it could be concluded that the pores in the $\mathrm{Co}_{3} \mathrm{O}_{4} / \mathrm{NPC}$ composites were mainly mesopores. 


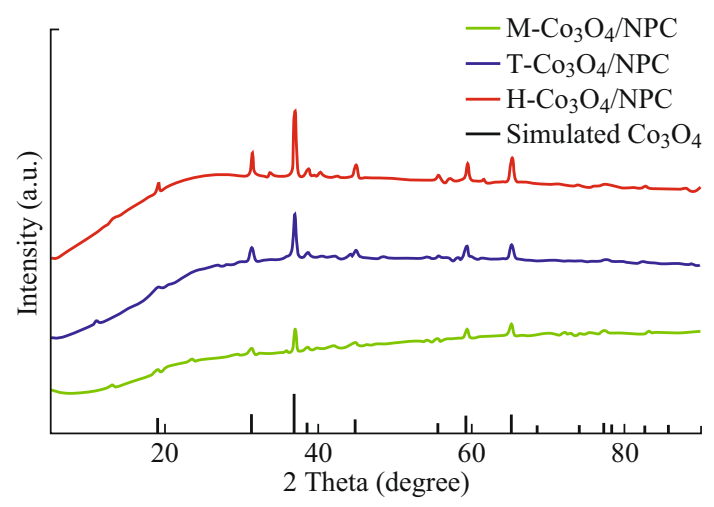

Fig. 4 PXRD patterns of $\mathrm{T}-\mathrm{Co}_{3} \mathrm{O}_{4} / \mathrm{NPC}, \mathrm{M}-\mathrm{Co}_{3} \mathrm{O}_{4} / \mathrm{NPC}$, and $\mathrm{H}-\mathrm{Co}_{3} \mathrm{O}_{4} / \mathrm{NPC}$ composites

The thermal stabilities of the three composites were investigated by TGA under air atmosphere. As shown in Fig. 6, heavy mass losses for M-ZIF-67, H-ZIF-67, and T-ZIF-67 started at 550, 300, and $400{ }^{\circ} \mathrm{C}$, respectively. When the temperature increased to $950{ }^{\circ} \mathrm{C}$, the weights remained at $44.85 \%, 11.17 \%$, and $36.96 \%$, respectively. The dramatic weight loss was attributed to the combustion of the carbon species. It is noteworthy that both H-ZIF-67 and
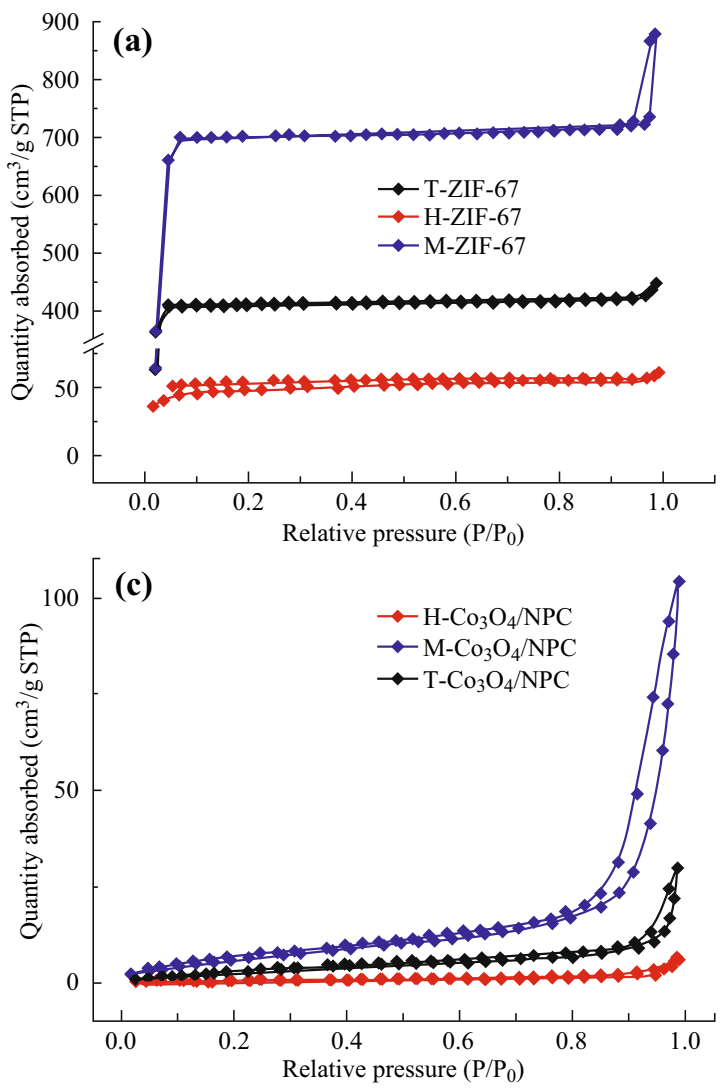

T-ZIF-67 went through a slight mass loss before decomposition, while M-ZIF-67 was stable below $500{ }^{\circ} \mathrm{C}$. This phenomenon indicated that the thermal stability of M-ZIF67 was much superior to that of H-ZIF-67 and T-ZIF-67.

Figure 7 shows the XPS results of the $\mathrm{M}-\mathrm{Co}_{3} \mathrm{O}_{4} / \mathrm{NPC}$ catalyst. As shown in Fig. 7a, the full XPS spectra provided evidence for the presence of $\mathrm{Co}, \mathrm{O}$, and $\mathrm{C}$. For the regional Co $2 p$ spectrum, two major peaks at 780.0 and $795.0 \mathrm{eV}$ were observed, which were correlated to the $\mathrm{Co}$ $2 p_{3 / 2}$ and Co $2 p_{1 / 2}$ spin-orbit peaks of $\mathrm{Co}_{3} \mathrm{O}_{4}$, respectively. In addition, two shakeup satellites, which were characteristic of $\mathrm{Co}_{3} \mathrm{O}_{4}$, were clearly observed at 789.9 and $804.3 \mathrm{eV}$ [38]. The high-resolution spectrum of O $1 s$ could be deconvoluted to three subpeaks (Fig. 7d). Peaks centered at 530.0 and $531.6 \mathrm{eV}$ were assigned to the lattice oxygen (denoted as $\mathrm{O}_{\mathrm{L}}$ ) in the $\mathrm{Co}_{3} \mathrm{O}_{4}$ phase and the $\mathrm{O}^{2-}$ ions in oxygen-deficient regions within the matrix of $\mathrm{Co}_{3} \mathrm{O}_{4}$ (denoted as $\mathrm{O}_{\mathrm{D}}$ ), respectively. The peak at $533.0 \mathrm{eV}$ was attributed to the absorbed oxygen species $\left(\mathrm{O}_{\mathrm{A}}\right)$. The percentage of $\mathrm{O}_{\mathrm{D}}$ in the total oxygen content related to the defect sites was calculated from the spectrum as $41.5 \%$. Such a high percentage of defect sites-related oxygen supported the high electrocatalytic performance of the
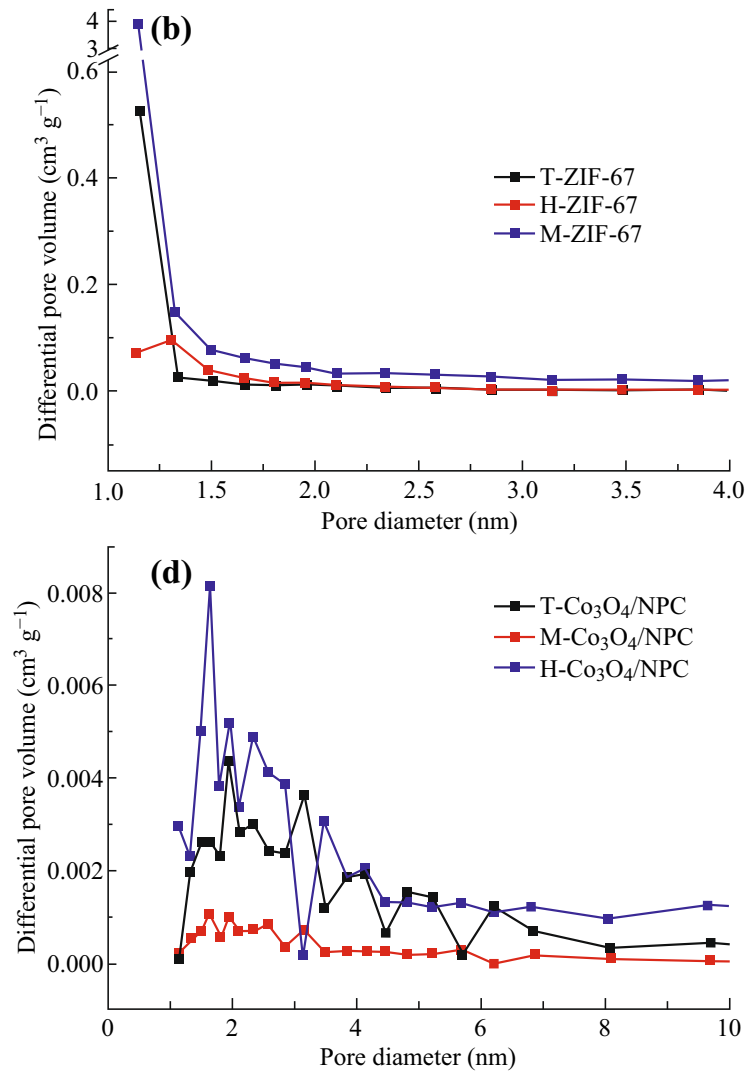

Fig. 5 a Nitrogen absorption-desorption isotherms and b pore size distributions of M-ZIF-67, H-ZIF-67, and T-ZIF-67. c Nitrogen absorptiondesorption isotherms and $\mathbf{d}$ pore size distributions of $\mathrm{T}-\mathrm{Co}_{3} \mathrm{O}_{4} / \mathrm{NPC}, \mathrm{M}-\mathrm{Co}_{3} \mathrm{O}_{4} / \mathrm{NPC}$, and $\mathrm{H}-\mathrm{Co}_{3} \mathrm{O}_{4} / \mathrm{NPC}$ composites 


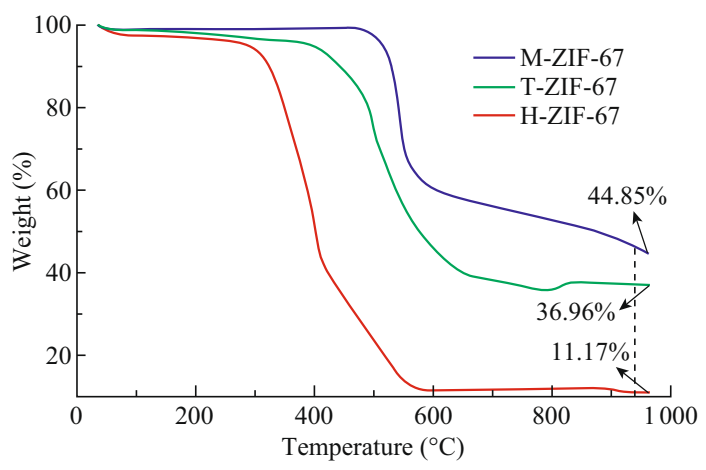

Fig. 6 TGA curves of M-ZIF-67, H-ZIF-67, and T-ZIF-67

$\mathrm{M}-\mathrm{Co}_{3} \mathrm{O}_{4} / \mathrm{NPC}$ composite. The $\mathrm{C} 1 s$ spectrum was deconvoluted into four subpeaks. The peak at $284.62 \mathrm{eV}$ was attributed to the $s p^{2}$-hybridized graphite-like carbon $(\mathrm{C}-\mathrm{C}$ $s p^{2}$ ), and the peak at $285.11 \mathrm{eV}$ was correlated to both the $s p^{3}$-hybridized diamond-like carbon $\left(\mathrm{C}-\mathrm{C} s p^{3}\right)$ and the $s p^{2}$ hybridized nitrogen-bonded carbon $\left(\mathrm{C}-\mathrm{N} s p^{2}\right)$. The other two peaks centered at 286.19 and $288.70 \mathrm{eV}$ were assigned to the carbon bonded with surface oxygen and nitrogen
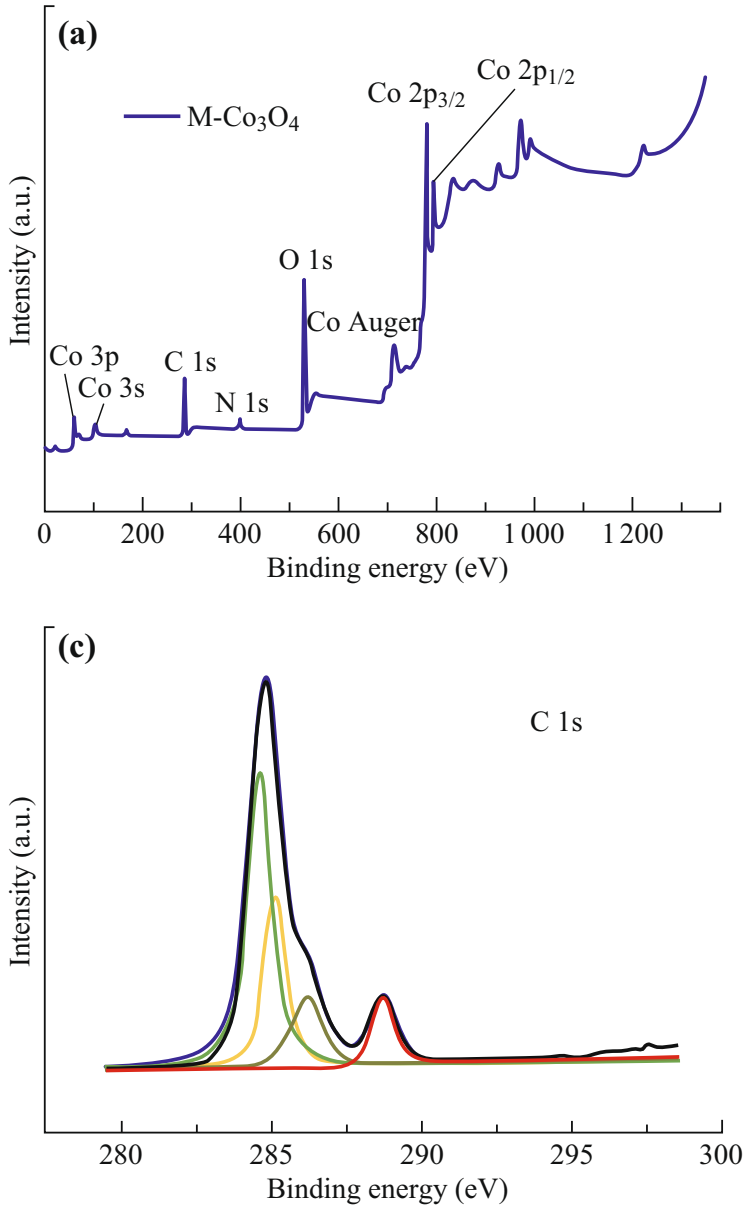

groups $(\mathrm{C}=\mathrm{O} / \mathrm{C}=\mathrm{N}, \mathrm{O}=\mathrm{C}-\mathrm{O}$, and $\mathrm{C}-\mathrm{O} / \mathrm{C}-\mathrm{N})$, respectively $[22,39]$.

To determine the optimum pyrolysis temperature for OER, the flower-like ZIF-67 was pyrolyzed at different temperatures $\left(350,450,550\right.$, and $\left.650{ }^{\circ} \mathrm{C}\right)$. The electrochemical activities of M-350, M-450, M-550, and M-650 for OER were tested in $\mathrm{O}_{2}$-saturated 1.0 M KOH solution. The over-potential at a current density of $10 \mathrm{~mA} \mathrm{~cm}^{-2}$ is an important metric related to solar fuel synthesis. As shown in the LSV curves (Fig. 8a), M-350, M-450, and M-550 showed comparative catalytic activity, and the overpotentials at a current density of $10 \mathrm{~mA} \mathrm{~cm} \mathrm{~cm}^{-2}$ were 290 , 310 , and $302 \mathrm{mV}$, respectively. M-650 displayed a relatively poor catalytic activity with a high over-potential $(\sim 370 \mathrm{mV})$. However, the Tafel slopes revealed the opposite tendency. Tafel plots were established based on the LSV curves (Fig. 8b). The Tafel slope $b$ is a parameter that describes the kinetics of the electrocatalyst for OER, which is determined by the Tafel equation:

$\eta=a+b \log |J|$
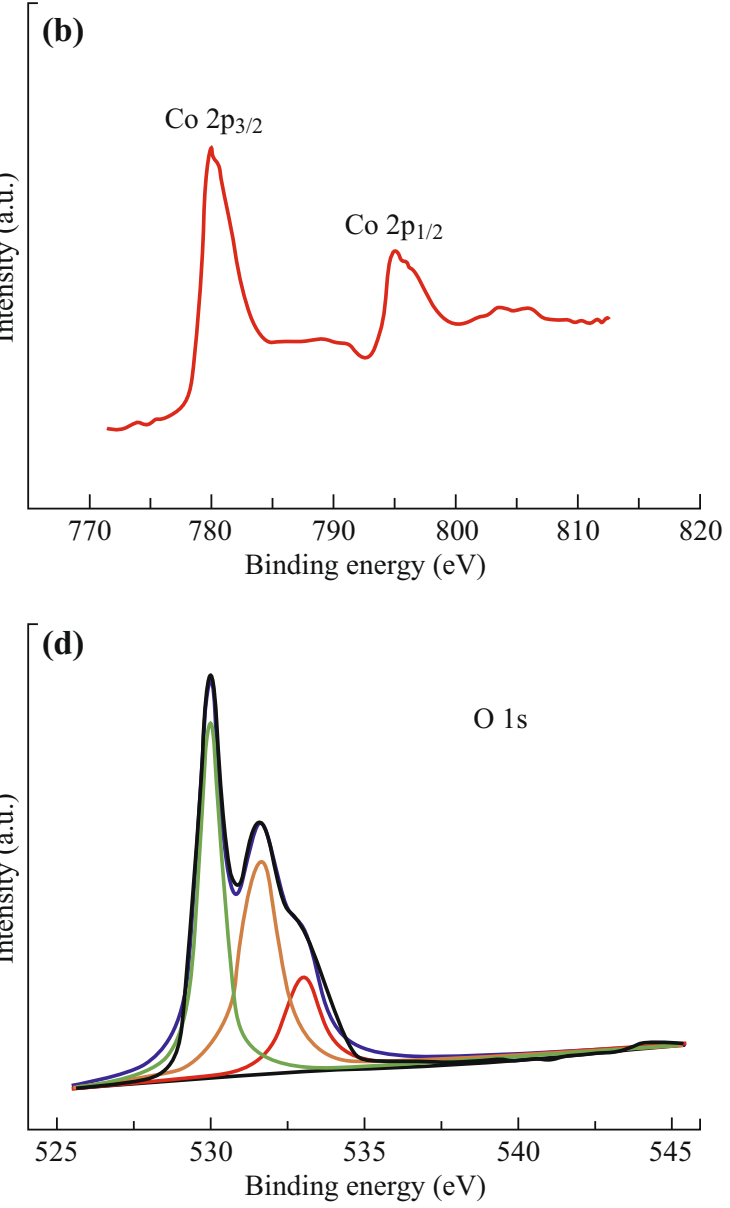

Fig. 7 a Full XPS spectrum of $\mathrm{M}-\mathrm{Co}_{3} \mathrm{O}_{4} / \mathrm{NPC}$, deconvoluted spectra of b Co $2 p$, c C $1 s$, and $\mathbf{d} \mathrm{O} 1 s$ 

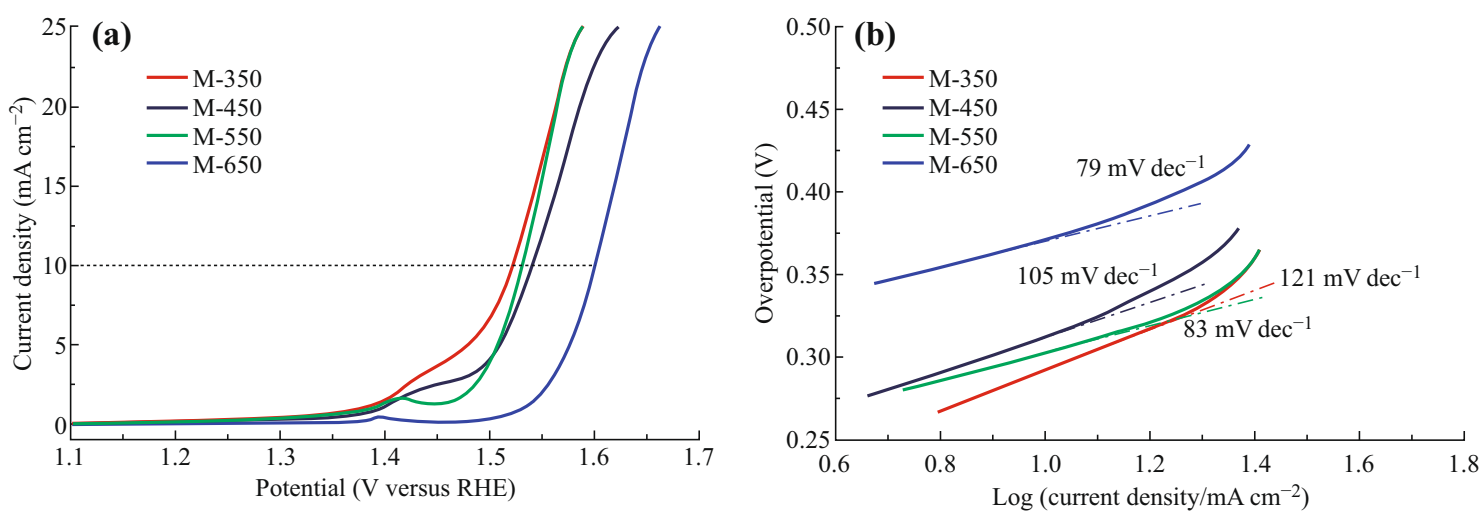

Fig. 8 a LSV curves of M-350, M-450, M-550, and M-650 in $\mathrm{O}_{2}$-saturated $1.0 \mathrm{M} \mathrm{KOH}$ solution (scan rate $5 \mathrm{mV} \mathrm{s}^{-1}$ ), b Tafel plots of the synthesized catalysts

where $\eta$ refers to the over-potential, $b$ represents the Tafel slope, and the current density is indicated by $J$. A smaller value of $b$ implies a faster increase in the rate of the OER as applied to an increase in the potential. The Tafel slope values for M-550 and M-650 were 83 and $79 \mathrm{~mA} \mathrm{dec}{ }^{-1}$, much smaller than those of M-350 $\left(\sim 121 \mathrm{~mA} \mathrm{dec}^{-1}\right)$ and $\mathrm{M}-450\left(\sim 105 \mathrm{~mA} \mathrm{dec}^{-1}\right)$. In order to explain these results, the composition and structure analysis was performed by powder XRD. As shown in Fig. S4, the intensity of the diffraction peaks of $\mathrm{Co}_{3} \mathrm{O}_{4}$ increased with the pyrolysis temperature, indicating a highly disordered structure of M-350. As the TGA results (Fig. 6) revealed that there was no obvious weight loss from the M-ZIF-67 sample at $350{ }^{\circ} \mathrm{C}$, it was reasonable to conclude that M-350 contained a high percentage of carbon. While a highly disordered structure efficiently improved the catalytic activity, the kinetics were compromised by the high carbon content. Remarkably, M-550 performed well in both metrics. Therefore, the optimum pyrolysis temperature was chosen as $550{ }^{\circ} \mathrm{C}$.

Therefore, M-ZIF-67, H-ZIF-67, and T-ZIF-67 were pyrolyzed at $550{ }^{\circ} \mathrm{C}$ under air. As shown in the LSV curves
(Fig. 9a), $\mathrm{H}-\mathrm{Co}_{3} \mathrm{O}_{4} / \mathrm{NPC}$ and $\mathrm{T}-\mathrm{Co}_{3} \mathrm{O}_{4} / \mathrm{NPC}$ exhibited relatively poor catalytic activity with onset potentials of 1.48 and $1.55 \mathrm{~V}$, respectively, while $\mathrm{M}-\mathrm{Co}_{3} \mathrm{O}_{4} / \mathrm{NPC}$ displayed a higher OER response with a low onset potential of $1.41 \mathrm{~V}$. Among the three samples, $\mathrm{M}_{-} \mathrm{Co}_{3} \mathrm{O}_{4} / \mathrm{NPC}$ afforded a current density of $10 \mathrm{~mA} \mathrm{~cm}{ }^{-2}$ at an over-potential of $302 \mathrm{mV}$, which was lower than those of $\mathrm{H}-\mathrm{Co}_{3} \mathrm{O}_{4} / \mathrm{NPC}$ $(\sim 317 \mathrm{mV})$ and $\mathrm{T}-\mathrm{Co}_{3} \mathrm{O}_{4} / \mathrm{NPC}(\sim 388 \mathrm{mV})$, indicating that a flower-like morphology was more favorable for OER. The Tafel slope value for $\mathrm{M}-\mathrm{Co}_{3} \mathrm{O}_{4} / \mathrm{NPC}$ was $84 \mathrm{~mA}$ $\mathrm{dec}^{-1}$, lower than those of $\mathrm{H}-\mathrm{Co}_{3} \mathrm{O}_{4} / \mathrm{NPC}\left(94 \mathrm{~mA} \mathrm{dec}{ }^{-1}\right)$ and $\mathrm{T}-\mathrm{Co}_{3} \mathrm{O}_{4} / \mathrm{NPC}\left(107 \mathrm{~mA} \mathrm{dec}{ }^{-1}\right)$ as well. These results suggested that the $\mathrm{M}-\mathrm{Co}_{3} \mathrm{O}_{4} / \mathrm{NPC}$ composite derived from the flower-like ZIF-67 exhibited superior catalytic activity over $\mathrm{T}-\mathrm{Co}_{3} \mathrm{O}_{4} / \mathrm{NPC}$ and $\mathrm{H}-\mathrm{Co}_{3} \mathrm{O}_{4} / \mathrm{NPC}$, which had been derived from rhombic dodecahedron and hollow spherical ZIF-67.

Strong durability toward OER is of great significance for energy conversion and storage systems. The chronoamperometric responses of $\mathrm{M}-\mathrm{Co}_{3} \mathrm{O}_{4} / \mathrm{NPC}, \mathrm{H}-\mathrm{Co}_{3} \mathrm{O}_{4} / \mathrm{NPC}$, and $\mathrm{T}-\mathrm{Co}_{3} \mathrm{O}_{4} / \mathrm{NPC}$ were determined at constant potentials of $1.53,1.55$, and $1.62 \mathrm{~V}$, respectively. As shown in
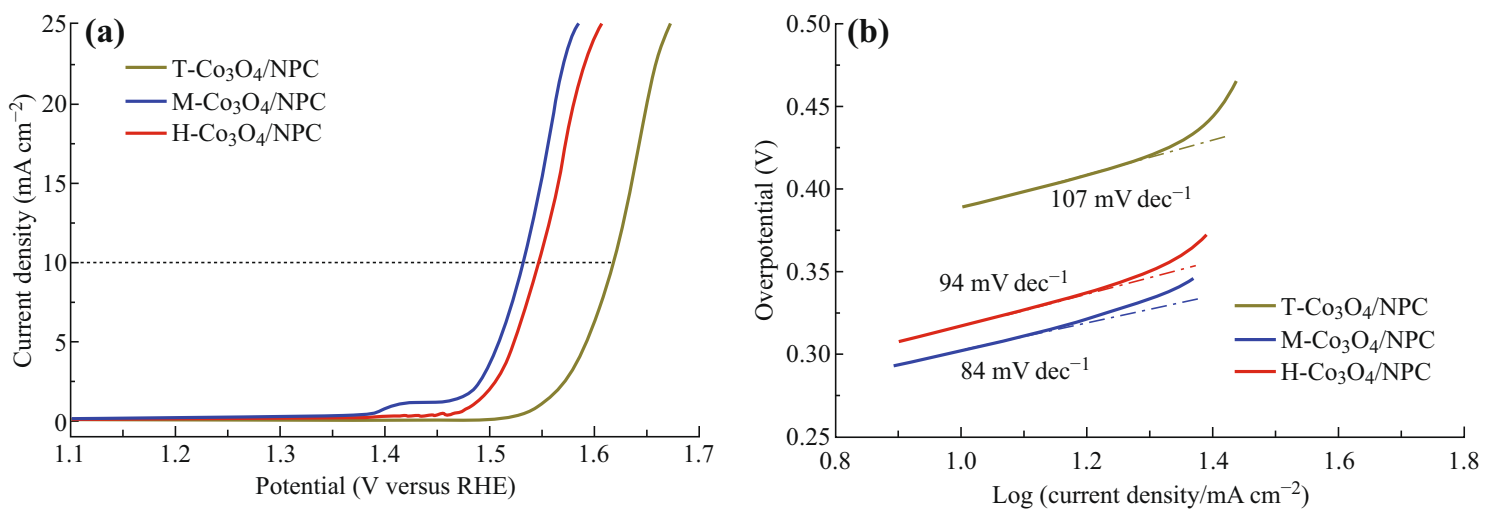

Fig. 9 a $\mathrm{LSV}$ curves of the $\mathrm{M}-\mathrm{Co}_{3} \mathrm{O}_{4} / \mathrm{NPC}, \mathrm{H}-\mathrm{Co}_{3} \mathrm{O}_{4} / \mathrm{NPC}$, and $\mathrm{T}-\mathrm{Co}_{3} \mathrm{O}_{4} / \mathrm{NPC}$ composites in $\mathrm{O}_{2}$-saturated $1.0 \mathrm{M}$ KOH solution (scan rate $5 \mathrm{mV} \mathrm{s}^{-1}$ ), b Tafel plots of the prepared catalysts 


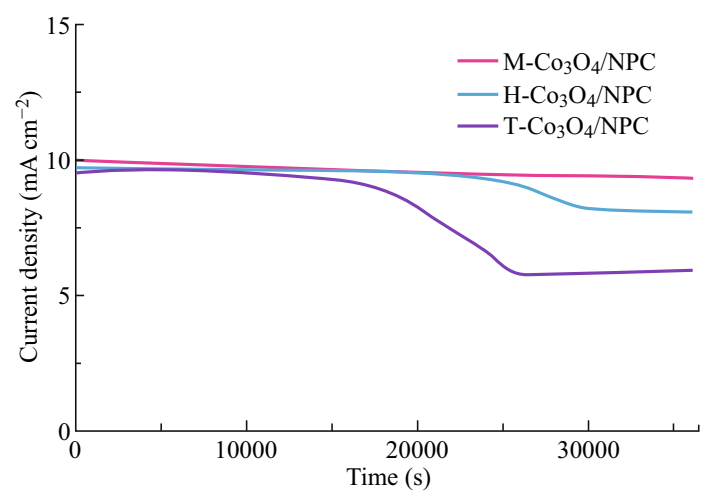

Fig. 10 Chronoamperometric responses of the $\mathrm{M}-\mathrm{Co}_{3} \mathrm{O}_{4} / \mathrm{NPC}$, $\mathrm{H}-\mathrm{Co}_{3} \mathrm{O}_{4} / \mathrm{NPC}$, and $\mathrm{T}-\mathrm{Co}_{3} \mathrm{O}_{4} / \mathrm{NPC}$ composites at constant potentials of $1.53,1.62$, and $1.55 \mathrm{~V}$, respectively

Fig. 10, $\mathrm{M}-\mathrm{Co}_{3} \mathrm{O}_{4} / \mathrm{NPC}$ displayed superior stability in comparison with $\mathrm{H}-\mathrm{Co}_{3} \mathrm{O}_{4} / \mathrm{NPC}$ and $\mathrm{T}-\mathrm{Co}_{3} \mathrm{O}_{4} / \mathrm{NPC}$, with only a slight anodic current attenuation of $5.3 \%$ within $10 \mathrm{~h}$. This result was attributed to the excellent structural stability of the flower-like carbon scaffold, which was also evident by the TGA results. Notably, the $\mathrm{M}-\mathrm{Co}_{3} \mathrm{O}_{4} / \mathrm{NPC}$ composite showed a better OER activity compared to not only most Co-based electrocatalysts, but also noble metalbased catalysts. A comprehensive comparison with previously reported catalysts is given in Table 1 .
The reason for better electrocatalytic performance of $\mathrm{M}-\mathrm{Co}_{3} \mathrm{O}_{4} / \mathrm{NPC}$ over the other two composites was attributed to its favorable structure (Fig. 11). Firstly, the $\mathrm{M}-\mathrm{Co}_{3} \mathrm{O}_{4} / \mathrm{NPC}$ composite derived from the flower-like ZIF-67 was comprised of the nitrogen-doped carbon scaffold with uniformly attached $\mathrm{Co}_{3} \mathrm{O}_{4}$ nanoparticles. The unique carbon network provided channels for the electrolyte, allowing intimate contact between the electrode and the electrolyte, hence promoting interfacial charge transfer. Besides, good electrical conductivity of the carbon scaffold likely also facilitated the electron transport. Thirdly, a highly disordered structure implied the presence of more active sites, which were key to the improvement in OER activity. Furthermore, the flower-like carbon matrix showed high structural stability, which could firmly support the $\mathrm{Co}_{3} \mathrm{O}_{4}$ nanoparticles and thus improved the stability of the catalyst.

\section{Conclusion}

In summary, a facile method for the preparation of $\mathrm{Co}_{3} \mathrm{O}_{4} /$ NPC composites with different morphologies has been proposed, in which $\mathrm{Co}_{3} \mathrm{O}_{4}$ nanoparticles were uniformly embedded in a nitrogen-doped carbon scaffold. By slightly modulating the synthetic route of the ZIF-67 precursors, it

Table 1 Comparison of electrocatalytic activity with previous reported catalysts

\begin{tabular}{|c|c|c|c|c|c|}
\hline Catalysts & $\mathrm{OP}^{\mathrm{a}}(\mathrm{V})$ & $\eta^{\mathrm{b}}(\mathrm{V})\left(\right.$ at $\left.10 \mathrm{~mA} \mathrm{~cm}^{-2}\right)$ & $\mathrm{TS}^{\mathrm{c}}\left(\mathrm{mV} \mathrm{dec}{ }^{-1}\right)$ & Electrolyte & References \\
\hline Porous $\mathrm{Co}_{3} \mathrm{O}_{4}$ nanoplates & 1.514 & 0.523 & 71 & $0.1 \mathrm{M} \mathrm{KOH}$ & [40] \\
\hline $\mathrm{Co}_{3} \mathrm{O}_{4} /$ mildly oxidized MCNT & 1.51 & 0.39 & 65 & $0.1 \mathrm{M} \mathrm{KOH}$ & {$[41]$} \\
\hline $\mathrm{CoO} / \mathrm{N}$-doped crumpled graphene & N. A. & 0.34 & 71 & $0.1 \mathrm{M} \mathrm{KOH}$ & [42] \\
\hline Au-meso- $\mathrm{Co}_{3} \mathrm{O}_{4}$ & 1.53 & 0.44 & 46 & $0.1 \mathrm{M} \mathrm{KOH}$ & {$[43]$} \\
\hline Hollow $\mathrm{Ni}-\mathrm{Co}$ oxide nanosponges & 1.50 & 0.36 & 61 & $0.1 \mathrm{M} \mathrm{KOH}$ & [44] \\
\hline Rutile $\mathrm{RuO}_{2}$ & $>1.70$ & 141 & N. A. & $0.1 \mathrm{M} \mathrm{KOH}$ & {$[45]$} \\
\hline $\mathrm{IrO}_{2} / \mathrm{C}$ & N. A. & 0.37 & N. A. & $0.1 \mathrm{M} \mathrm{KOH}$ & {$[21]$} \\
\hline This work & 1.41 & 0.30 & 84 & $0.1 \mathrm{M} \mathrm{KOH}$ & - \\
\hline
\end{tabular}

${ }^{\mathrm{a}} \mathrm{OP}=$ onset potential; ${ }^{\mathrm{b}} \eta=$ over-potential at current density of $10 \mathrm{~mA} \mathrm{~cm}{ }^{-2} ;{ }^{\mathrm{c}} \mathrm{TS}=$ Tafel slope
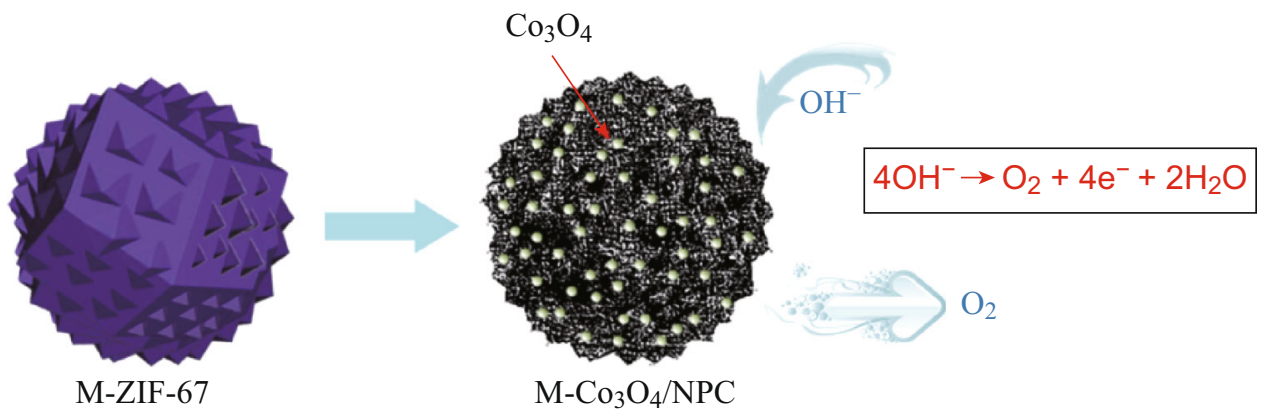

Fig. 11 Schematic diagram of the $\mathrm{M}-\mathrm{Co}_{3} \mathrm{O}_{4} / \mathrm{NPC}$ structure 
was possible to achieve control of their morphology. This facile method provided a new means to prepare MOFderived electrocatalysts for the OER. Among the three $\mathrm{Co}_{3} \mathrm{O}_{4} / \mathrm{NPC}$ composites, the $\mathrm{M}-\mathrm{Co}_{3} \mathrm{O}_{4} / \mathrm{NPC}$ derived from the flower-like ZIF-67 displayed superior electrocatalytic activity. The excellent performance of the $\mathrm{M}-\mathrm{Co}_{3} \mathrm{O}_{4} / \mathrm{NPC}$ composite was attributed to its favorable structure. Firstly, the unique carbon network allowed an intimate contact area between the electrode and the electrolyte, thus promoting interfacial charge transfer. Secondly, the highly disordered structure resulted in more active sites, which were determinant to the electrocatalytic activity for OER. Lastly, the flower-like carbon matrix assumed high structural stability, which firmly supported the $\mathrm{Co}_{3} \mathrm{O}_{4}$ nanoparticles, thus improving the stability of the catalyst.

Acknowledgements This work was supported by the Scientific and Technological Innovation Platform of Fujian Province (2006L2003) and Scientific Research Project of Wuyi University (YJ201706).

Open Access This article is distributed under the terms of the Creative Commons Attribution 4.0 International License (http://crea tivecommons.org/licenses/by/4.0/), which permits unrestricted use, distribution, and reproduction in any medium, provided you give appropriate credit to the original author(s) and the source, provide a link to the Creative Commons license, and indicate if changes were made.

\section{References}

1. M. Winter, R.J. Brodd, What are batteries, fuel cells, and supercapacitors? Chem. Rev. 105(3), 1021 (2005). https://doi.org/ 10.1021/cr040110e

2. S. Chu, A. Majumdar, Opportunities and challenges for a sustainable energy future. Nature 488(7411), 294-303 (2012). https://doi.org/10.1038/nature11475

3. P. Zhang, J.J. Zhang, J.L. Gong, Tantalum-based semiconductors for solar water splitting. Chem. Soc. Rev. 43(13), 4395-4422 (2014). https://doi.org/10.1039/c3cs60438a

4. J.S. Liang, K.Y. Liu, S.Z. Li, D.Z. Wang, T.Q. Ren, X.Y. Xu, Y. Luo, Novel flow field with superhydrophobic gas channels prepared by one-step solvent-induced crystallization for micro direct methanol fuel cell. Nano-Micro Lett. 7(2), 165-171 (2015). https://doi.org/10.1007/s40820-015-0032-x

5. T.W. Kim, K.S. Choi, Nanoporous $\mathrm{BiVO}_{4}$ photoanodes with dual-layer oxygen evolution catalysts for solar water splitting. Science 343(6174), 990-994 (2014). https://doi.org/10.1126/sci ence. 1246913

6. M. Zhang, M. de Respinis, H. Frei, Time-resolved observations of water oxidation intermediates on a cobalt oxide nanoparticle catalyst. Nat. Chem. 6(4), 362-367 (2014). https://doi.org/10. 1038/Nchem. 1874

7. K. Guo, Y. Li, J. Yang, Z.Q. Zou, X.Z. Xue, X.M. Li, H. Yang, Nanosized $\mathrm{Mn}-\mathrm{Ru}$ binary oxides as effective bifunctional cathode electrocatalysts for rechargeable $\mathrm{LiO}_{2}$ batteries. J. Mater. Chem. A 2(5), 1509-1514 (2014). https://doi.org/10.1039/ c3ta13176a

8. G.L. Tian, M.Q. Zhao, D.S. Yu, X.Y. Kong, J.Q. Huang, Q. Zhang, F. Wei, Nitrogen-doped graphene/carbon nanotube hybrids: in situ formation on bifunctional catalysts and their superior electrocatalytic activity for oxygen evolution/reduction reaction. Small 10(11), 2251-2259 (2014). https://doi.org/10. 1002/smll.201303715

9. A.R. Parent, K. Sakai, Progress in base-metal water oxidation catalysis. Chemsuschem 7(8), 2070-2080 (2014). https://doi.org/ $10.1002 /$ cssc. 201402322

10. K. Jin, J. Park, J. Lee, K.D. Yang, G.K. Pradhan et al., Hydrated manganese(II) phosphate $\left(\mathrm{Mn}-3\left(\mathrm{PO}_{4}\right)(2)\right.$ center dot $\left.3 \mathrm{H}(2) \mathrm{O}\right)$ as a water oxidation catalyst. J. Am. Chem. Soc. 136(20), 7435-7443 (2014). https://doi.org/10.1021/ja5026529

11. M. Gong, Y.G. Li, H.L. Wang, Y.Y. Liang, J.Z. Wu et al., An advanced $\mathrm{Ni}-\mathrm{Fe}$ layered double hydroxide electrocatalyst for water oxidation. J. Am. Chem. Soc. 135(23), 8452-8455 (2013). https://doi.org/10.1021/ja4027715

12. R. Subbaraman, D. Tripkovic, K.C. Chang, D. Strmcnik, A.P. Paulikas et al., Trends in activity for the water electrolyser reactions on $3 \mathrm{~d} \mathrm{M}(\mathrm{Ni} \mathrm{Co}, \mathrm{Fe}, \mathrm{Mn})$ hydr(oxy)oxide catalysts. Nat. Mater. 11(6), 550-557 (2012). https://doi.org/10.1038/ NMAT3313

13. M. Xing, L.B. Kong, M.C. Liu, L.Y. Liu, L. Kang, Y.C. Luo, Cobalt vanadate as highly active, stable, noble metal-free oxygen evolution electrocatalyst. J. Mater. Chem. A 2(43), 18435-18443 (2014). https://doi.org/10.1039/c4ta03776f

14. D. Phihusut, J.D. Ocon, B. Jeong, J.W. Kim, J.K. Lee, J. Lee, Gently reduced graphene oxide incorporated into cobalt oxalate rods as bifunctional oxygen electrocatalyst. Electrochim. Acta 140(27), 404-411 (2014). https://doi.org/10.1016/j.electacta. 2014.05.050

15. T.L. Wee, B.D. Sherman, D. Gust, A.L. Moore, T.A. Moore, Y. Liu, J.C. Scaiano, Photochemical synthesis of a water oxidation catalyst based on cobalt nanostructures. J. Am. Chem. Soc. 133(42), 16742-16745 (2011). https://doi.org/10.1021/ja206280g

16. H.X. Zhao, Z. Zheng, J. Li, H.M. Jia, K.W. Wong, Y.D. Zhang, W.M. Lau, Substitute of expensive Pt with improved electrocatalytic performance and higher resistance to $\mathrm{CO}$ poisoning for methanol oxidation: the case of synergistic $\mathrm{Pt}_{-} \mathrm{Co}_{3} \mathrm{O}_{4}$ nanocomposite. Nano-Micro Lett. 5(4), 296-302 (2013). https://doi.org/10. 5101/nml.v5i4.p296-302

17. Y.J. Sa, K. Kwon, J.Y. Cheon, F. Kleitz, S.H. Joo, Ordered mesoporous $\mathrm{Co}_{3} \mathrm{O}_{4}$ spinels as stable, bifunctional, noble metalfree oxygen electrocatalysts. J. Mater. Chem. A 1(34), 9992-10001 (2013). https://doi.org/10.1039/c3ta11917c

18. T. Grewe, X.H. Deng, C. Weidenthaler, F. Schuth, H. Tuysuz, Design of ordered mesoporous composite materials and their electrocatalytic activities for water oxidation. Chem. Mater. 25(24), 4926-4935 (2013). https://doi.org/10.1021/cm403153u

19. X. Leng, Q.C. Zeng, K.H. Wu, I.R. Gentle, D.W. Wang, Reduction-induced surface amorphization enhances the oxygen evolution activity in $\mathrm{Co}_{3} \mathrm{O}_{4}$. RSC Adv. 5(35), 27823-27828 (2015). https://doi.org/10.1039/c5ra00995b

20. A. Bergmann, E. Martinez-Moreno, D. Teschner, P. Chernev, M. Gliech, J.F. de Araujo, T. Reier, H. Dau, P. Strasser, Reversible amorphization and the catalytically active state of crystalline $\mathrm{Co}_{3} \mathrm{O}_{4}$ during oxygen evolution. Nat. Commun. 6, 8625 (2015). https://doi.org/10.1038/Ncomms9625

21. Y. Zhao, R. Nakamura, K. Kamiya, S. Nakanishi, K. Hashimoto, Nitrogen-doped carbon nanomaterials as non-metal electrocatalysts for water oxidation. Nat. Commun. 4, 2390 (2013). https:// doi.org/10.1038/Ncomms3390

22. T.C. Nagaiah, A. Bordoloi, M.D. Sanchez, M. Muhler, W. Schuhmann, Mesoporous nitrogen-rich carbon materials as catalysts for the oxygen reduction reaction in alkaline solution. Chemsuschem 5(4), 637-641 (2012). https://doi.org/10.1002/ cssc. 201100284 
23. K.P. Gong, F. Du, Z.H. Xia, M. Durstock, L.M. Dai, Nitrogendoped carbon nanotube arrays with high electrocatalytic activity for oxygen reduction. Science 323(5915), 760-764 (2009). https://doi.org/10.1126/science.1168049

24. Y.Y. Liang, Y.G. Li, H.L. Wang, J.G. Zhou, J. Wang, T. Regier, H.J. Dai, $\mathrm{Co}_{3} \mathrm{O}_{4}$ nanocrystals on graphene as a synergistic catalyst for oxygen reduction reaction. Nat. Mater. 10(10), 780-786 (2011). https://doi.org/10.1038/NMAT3087

25. P. Chen, T.Y. Xiao, Y.H. Qian, S.S. Li, S.H. Yu, A nitrogendoped graphene/carbon nanotube nanocomposite with synergistically enhanced electrochemical activity. Adv. Mater. 25(23), 3192-3196 (2013). https://doi.org/10.1002/adma.201300515

26. Y. Wei, X.Y. Zhang, Z.Y. Luo, D. Tang, C.X. Chen, T. Zhang, Z.L. Xie, Nitrogen-doped carbon nanotube-supported Pd catalyst for improved electrocatalytic performance toward ethanol electrooxidation. Nano-Micro Lett. 9(3), 28 (2017). https://doi.org/ 10.1007/s40820-017-0129-5

27. J.S. Lee, G.S. Park, S.T. Kim, M.L. Liu, J. Cho, A highly efficient electrocatalyst for the oxygen reduction reaction: $\mathrm{N}$-doped ketjenblack incorporated into $\mathrm{Fe} / \mathrm{Fe}_{3} \mathrm{C}$-functionalized melamine foam. Angew. Chem. Int. Ed. 52(3), 1026-1030 (2013). https:// doi.org/10.1002/anie.201207193

28. R. Silva, D. Voiry, M. Chhowalla, T. Asefa, Efficient metal-free electrocatalysts for oxygen reduction: polyaniline-derived $\mathrm{N}$ - and O-doped mesoporous carbons. J. Am. Chem. Soc. 135(21), 7823-7826 (2013). https://doi.org/10.1021/ja402450a

29. J.T. Zhang, Z.H. Zhao, Z.H. Xia, L.M. Dai, A metal-free bifunctional electrocatalyst for oxygen reduction and oxygen evolution reactions. Nat. Nanotechnol. 10(5), 444-452 (2015). https://doi.org/10.1038/Nnano.2015.48

30. G. Wu, K.L. More, C.M. Johnston, P. Zelenay, High-performance electrocatalysts for oxygen reduction derived from polyaniline, iron, and cobalt. Science 332(6028), 443-447 (2011). https://doi. org/10.1126/science. 1200832

31. J. Du, F.Y. Cheng, S.W. Wang, T.R. Zhang, J. Chen, M(Salen)derived nitrogen-doped $\mathrm{M} / \mathrm{C} \quad(\mathrm{M}=\mathrm{Fe} \mathrm{Co}, \mathrm{Ni})$ porous nanocomposites for electrocatalytic oxygen reduction. Sci. Rep. 4, 4368 (2014). https://doi.org/10.1038/Srep04386

32. Y.Q. Chen, J.T. Li, G.H. Yue, X.T. Luo, Novel Ag@nitrogendoped porous carbon composite with high electrochemical performance as anode materials for lithium-ion batteries. Nano-Micro Lett. 9(3), 32 (2017). https://doi.org/10.1007/s40820-0170131-y

33. C. Li, T. Chen, W. Xu, X. Lou, L. Pan, Q. Chen, B. Hu, Mesoporous nanostructured $\mathrm{Co}_{3} \mathrm{O}_{4}$ derived from MOF template: a high-performance anode material for lithium-ion batteries. J. Mater. Chem. A 3(10), 5585-5591 (2015). https://doi.org/10. 1039/c4ta06914e

34. H.Z. Liu, G.L. Xia, R.R. Zhang, P. Jiang, J.T. Chen, Q.W. Chen, MOF-derived $\mathrm{RuO}_{2} / \mathrm{Co}_{3} \mathrm{O}_{4}$ heterojunctions as highly efficient bifunctional electrocatalysts for HER and OER in alkaline solutions. RSC Adv. 7(7), 3686-3694 (2017). https://doi.org/10. 1039/c6ra25810g

35. R.P. Antony, A.K. Satpati, K. Bhattacharyya, B.N. Jagatap, MOF derived nonstoichiometric $\mathrm{NixCo}_{3-\mathrm{x}} \mathrm{O}_{4-\mathrm{y}}$ nanocage for superior electrocatalytic oxygen evolution. Adv. Mater. Interfaces 3(20), 1600632 (2016). https://doi.org/10.1002/admi.201600632

36. F.W. Ming, H.F. Liang, H.H. Shi, X. Xu, G. Mei, Z.C. Wang, MOF-derived Co-doped nickel selenide/C electrocatalysts supported on Ni foam for overall water splitting. J. Mater. Chem. A 4(39), 15148-15155 (2016). https://doi.org/10.1039/c6ta06496e

37. A.R. Millward, O.M. Yaghi, Metal-organic frameworks with exceptionally high capacity for storage of carbon dioxide at room temperature. J. Am. Chem. Soc. 127(51), 17998-17999 (2005). https://doi.org/10.1021/ja0570032

38. T. He, D.R. Chen, X.L. Jiao, Y.L. Wang, Y.Z. Duan, Solubilitycontrolled synthesis of high-quality $\mathrm{Co}_{3} \mathrm{O}_{4}$ nanocrystals. Chem. Mater. 17(15), 4023-4030 (2005). https://doi.org/10.1021/ $\mathrm{cm} 050727 \mathrm{~s}$

39. X.Z. Li, Y.Y. Fang, X.Q. Lin, M. Tian, X.C. An, Y. Fu, R. Li, J. Jin, J.T. Ma, MOF derived $\mathrm{Co}_{3} \mathrm{O}_{4}$ nanoparticles embedded in $\mathrm{N}$-doped mesoporous carbon layer/MWCNT hybrids: extraordinary bi-functional electrocatalysts for OER and ORR. J. Mater. Chem. A 3(33), 17392-17402 (2015). https://doi.org/10.1039/ c5ta03900b

40. X.M. Zhou, Z.M. Xia, Z.M. Tian, Y.Y. Ma, Y.Q. Qu, Ultrathin porous $\mathrm{Co}_{3} \mathrm{O}_{4}$ nanoplates as highly efficient oxygen evolution catalysts. J. Mater. Chem. A 3(15), 8107-8114 (2015). https://doi. org/10.1039/c4ta07214f

41. X.Y. Lu, C. Zhao, Highly efficient and robust oxygen evolution catalysts achieved by anchoring nanocrystalline cobalt oxides onto mildly oxidized multiwalled carbon nanotubes. J. Mater. Chem. A 1(39), 12053-12059 (2013). https://doi.org/10.1039/ c3ta12912h

42. S. Mao, Z.H. Wen, T.Z. Huang, Y. Hou, J.H. Chen, High-performance bi-functional electrocatalysts of $3 \mathrm{D}$ crumpled graphene-cobalt oxide nanohybrids for oxygen reduction and evolution reactions. Energy Environ. Sci. 7(2), 609-616 (2014). https://doi.org/10.1039/c3ee42696c

43. X.Y. Lu, Y.H. Ng, C. Zhao, Gold nanoparticles embedded within mesoporous cobalt oxide enhance electrochemical oxygen evolution. Chemsuschem 7(1), 82-86 (2014). https://doi.org/10. $1002 /$ cssc. 201300975

44. C.Z. Zhu, D. Wen, S. Leubner, M. Oschatz, W. Liu, M. Holzschuh, F. Simon, S. Kaskel, A. Eychmuller, Nickel cobalt oxide hollow nanosponges as advanced electrocatalysts for the oxygen evolution reaction. Chem. Commun. 51(37), 7851-7854 (2015). https://doi.org/10.1039/c5cc01558h

45. Y. Lee, J. Suntivich, K.J. May, E.E. Perry, Y. Shao-Horn, Synthesis and activities of rutile $\mathrm{IrO}_{2}$ and $\mathrm{RuO}_{2}$ nanoparticles for oxygen evolution in acid and alkaline solutions. J. Phys. Chem. Lett. 3(3), 399-404 (2012). https://doi.org/10.1021/jz2016507 